\title{
Investigate Road Safety in Developing Countries: The Case of Sri Lanka
}

\author{
Jayanetti, J. K. D. D. T ${ }^{1 *}$, Perera, B. A. K. S. ${ }^{2}$, Ariyawansa, K. T. C ${ }^{2}$. \\ ${ }^{1}$ General Sir John Kotelawala Defence University, Sri Lanka \\ ${ }^{2}$ Department of Building Economics, University of Moratuwa, Sri Lanka
}

\begin{abstract}
The social and economic burdens of road accidents have become a governing issue for the authorities and policymakers of developing countries. Moreover, the lack of research on road safety management has hindered the enhancement of road safety in these countries. Thus, this study aimed to improve the road safety standards in Sri Lanka. The objectives of the study are to investigate the causes of road accidents in Sri Lanka, to examine the problems associated with the road conditions existing in Sri Lanka and to propose strategies to improve road safety in Sri Lanka. A qualitative approach was adopted in the study and the empirical data collection commenced with a comprehensive document review to determine the level of road safety management in the country. Thereafter, case study strategy was adopted and three roads in Sri Lanka were selected through purposive sampling as the cases. Non-participatory observations and 20 semi-structured interviews were conducted to collect the required data from the three roads. The collected data were analyzed using code-based manual content analysis. The findings revealed that the roads in Sri Lanka have deficiencies. Eighteen causes of road traffic accidents and nineteen strategies that can enhance road safety in Sri Lanka were identified through the study. Related previous studies have revealed only the statistics, trends, and economic impacts of road accidents in developing countries. Thus, the literature on the management of road safety standards in developing countries is scarce and this study fulfils the research gap. The study adds to the body of knowledge by exploring in detail how the road safety standards in developing countries could be enhanced using Sri Lanka as an example.
\end{abstract}

Keywords: Causes, Road safety management, Road traffic accidents, Strategies.

\section{Introduction}

An important factor that determines the level of development of a country is the reliability and efficiency of its transportation system (Sakhapov \& Nikolaeva, 2018). A reliable and efficient transportation system can attract the public, manufacturing enterprises, and production forces, all of which together will have an integrated effect on the country (Batishcheva \& Ganichev, 2016). Traffic injuries have significant consequences in all countries (Lopez et al., 2016). However, pedestrian-vehicle interactions significantly differ from country to country because they depend on the road traffic conditions and how

\footnotetext{
$11 *$ Corresponding Author

https://orcid.org/0000-0002-1712-2210

e-mail: jkddlijayanetti@kdu.ac.lk
}

DOI: http://doi.org/10.4038/bhumi.v8i1.75 
well the road users comply with traffic rules (Alhajyaseen et al., 2012). Road safety in low-income countries remains a major concern. Because of the expected increase in traffic due to the rapid motorization of transport in low-income countries, the understanding of the underlying mechanisms of road safety is imperative (Heydari et al., 2019). According to Persia et al (2016), in lowincome countries, motorized vehicle uses, and related road safety issues are high in number.

A study by Liyange \& Santoso (2017) indicated that motorcycles are becoming popular in developing countries because they are economical despite their negative impacts on road safety. According to the statistics published by the World Health Organization (WHO), people living in a vast majority of lowand middle-income developing countries are prone to traffic-related fatalities (WHO, 2017).

Road traffic injuries are among the ten leading causes of mortality and morbidity worldwide and more than 1.2 million of the population is expected to die and about 50 million expected to get injured annually because of road traffic accidents (WHO, 2018). A study done by Bishai (2003) revealed that budgetary expenditure on road safety at all levels of the governments in Uganda and Pakistan is as low as $\$ 0.09$ and $\$ 0.07$ per capita, respectively. A study done by CalvoPoyo et al. (2020) proved that the higher the expenditure on road networks and maintenance, the lower is the road mortality, proving that in developing countries the low investments made on road safety has accelerated the rate of road related accidents.

The national road network in Sri Lanka (Class A and Class B Road network) serves $80 \%$ of the road traffic in the island (Nalaka \& Sivakumar, 2016). Sri Lanka, being a developing country, has witnessed an increase in road traffic crashes in the recent past (Dharmaratne et al., 2015) and the society has finally become concerned of road safety (Kumarage et al., 2003). Poor road safety in the country indicates its underinvestment in targeted initiatives. The country would require an additional investment of almost US\$ 2 billion over the coming decade, if it is to achieve target 3.6 of Sustainable Development Agenda by reducing the national roadcrash fatalities by 50 percent (UNCTAD, 2017).

The incidents of road traffic related injuries and deaths are escalating in the country. The burden of such crashes on vulnerable road users (elderly and disabled people), is important for traffic injury prevention and transport policy planning (Tennakoon et al., 2020). As stated by Bhavan (2019), the increasing number of road accidents in Sri Lanka has had a significant effect on the economic growth of the country, because of the increased expenditure that had to be incurred. Accordingly, road accidents have become a burden to Sri Lanka because they have worsened the economic problems of the country (Bhavan, 2019).

Because of the dearth of research on road safety in Sri Lanka and the limited availability of statistics on road traffic crashes that had occurred in the country and the resulting injuries, policymakers find it difficult to propose interventions that can prevent road traffic crashes (Dharmaratne et al., 2015). A study conducted by the World Bank (2020) emphasizes that among the many deficiencies related to road safety that need urgent attention, research and 
development, and knowledge transfer require high priority.

Several studies have already been done on road safety in Sri Lanka. Dharmaratne et al. (2015) analyzed road traffic crashes, injuries, and fatality trends in Sri Lanka. Amarasinghe \& Dharmarathna (2019) looked mainly at the epidemiology of road traffic crashes reported in the Kurunegala Police Division. Bhavan (2019) focused on the impact of road accidents on the economy of Sri Lanka. Tennakoon et al. (2020) discussed mainly the transport equity in Sri Lanka with regard to the experiences of the disabled people and the aged. Thus, there is a dearth of literature on enhancing road safety in Sri Lanka.

The aim of this study was, therefore, to enhance road safety in developing countries by taking Sri Lanka as an example. The key objectives of the study were to investigate the causes of road accidents in Sri Lanka, examine the problems associated with the current road conditions in the country, and propose strategies to improve road safety in the country.

\section{Literature Review}

\subsection{Road safety management}

Road safety management is the task of preparing and implementing road safety policies, which include defining of goals and targets, programming, implementing interventions, evaluation, and research (Alfonzi, 2016). Assuming that effective road safety management ensures sound road safety performance, Jähi et al. (2012) proposed an ideal road safety management model based on several "good practice" criteria. The model contains a set of activities that would ensure that all stakeholders involved in mobility and transportation follow the procedures that would minimize their vulnerability to road safety accidents (Persia et al., 2016).

A road safety management system should meet several "good practice" criteria. This is to span the entire policy-making cycle from agenda setting to policy formulation, adoption, implementation, and evaluation, and should contain an efficient structure and smooth processes to enable evidence-based policy making (Papadimitriou \& Yannis, 2013). Today, road safety management is considered as one of the most important issues that authorities have to handle. It requires a well-planned strategy and a design (Eusofe \& Evdorides, 2017). Because of its complexity, road safety management requires modern tools to identify road user risks; assess and evaluate the safety of road infrastructure; and select effective measures to improve road safety (Jamroz et al., 2014).

\subsection{Road Accidents in Developing Countries}

Road safety developments are correlated with socio-economic factors such as the level of motorization and economic growth, which differed significantly between developed and developing countries. This is evident when traffic safety data was comparatively analyzed in-between the selected developing countries and the European countries for the period of 2003-2013 (Jadaan et al., 2018).

A study conducted by Khanal \& Sarkar (2014) demonstrated that unlike to the high-income countries, low-income countries are facing a dire threat. The authors further elaborated that 134,513 people lost their lives due to road accidents in 2010, whereas only 32,885 
road fatalities were reported in the US during the same year. Another study conducted by Banerjee \& Maurya (2019) on road safety in India indicated that a large number of pedestrians are involved in road traffic accidents, the pedestrians being the most vulnerable segment of the public to such accidents.

A study by Verzosa \& Miles (2016) on road traffic accidents in Philippines, stated that pedestrians are the most vulnerable road users in low- and middleincome countries because of the inability of the built environments of these countries to accommodate the increasing number of vehicles on their roads. Road traffic injuries are one of the leading causes of deaths in the people aged 5-29. According to WHO (2018), 1.35 million people die and 20-50 million people are injured each year from road traffic accidents. Road traffic accidents are the most prominent causes of death in lowand middle-income countries with $93 \%$ of the road traffic -related deaths in the world occurring in these countries (Safarpour et al., 2020).

According to WHO (2020), more than $90 \%$ of the road traffic deaths in the world occur in low- and middle-income countries. Every year, more than 1 million road users are predicted to be killed and around 50 million road users injured in road accidents (Shoukrallah, 2008). Also, $30 \%$ to $70 \%$ of the children in the middle-income countries are affected by road accidents. The number of vehicles on the roads worldwide is expected to get doubled by 2030 by which time around $58 \%$ of the world population will be living in urban areas, and will, therefore, be prone to road accidents (Crandall et al., 2002). Road traffic crashes cause grief, suffering, and economic losses to the victims, their families, communities, and the nations as a whole.

In high-income countries, the cost of these crashes will amount to $3 \%$ of their gross national product on average, while in low- and middle-income countries this cost can go up to $5 \%$ of the gross national product. Indirect costs, such as the loss of productivity, damage to vehicles and property, reduction in the quality of life, also have to be considered when calculating the true cost of road traffic crashes to society (WHO, 2017). Highincome developed countries registered a remarkable decrease in road accident fatalities in the last decade because of the use of safer vehicles, roads, and road user behavior. In contrast, the situation in lowand middle-income developing countries is completely the opposite (WHO, 2013).

None of the countries in Southeast Asia have comprehensive legislation on five key factors associated with road traffic injuries- speed, drink-driving, use of motorcycle helmets, seatbelts, and child restraints (UNCTAD, 2017). During the past few years in Sri Lanka, mobility and motorization introduced different modes of travel that are unsafe on the existing roads due to high pedestrian movements along the roads (Kumarage, 2012). Jayarathne \& Kumarage (2006) highlighted that in 2002, 37\% of the accident fatalities were pedestrians due to the faults of the motorists. According to their analysis, only $5 \%$ of the pedestrians were responsible for the accidents.

In Sri Lanka, road-related crashes have been on the increase since 2009 (Department of Census and Statistics Sri Lanka, 2018). During the last fifteen years, 600 - 900 pedestrian fatalities had occurred annually, which is equivalent to approximately two pedestrian deaths per day. According to Amarasinghe \& 
Dharmaratne (2019), Sri Lanka, being a middle-income country (Word Bank, 2019), has to bear the burden of road traffic crashes, and associated injuries and deaths. This is because the growth of motorization on its static road system is exponential, making it necessary for the country to pay attention to road safety. The absence of road safety investigations and the inadequacy of the data available on road traffic accidents make it difficult for policymakers to propose solutions that will prevent road traffic accidents (Dharmaratne et al., 2015).

\subsection{Causes of road traffic accidents}

The causes of motor vehicle collisions, which are complex, broadly depend on the characteristics of the drivers (Rolison et al., 2018). The skill level (McGwin \& Brown, 1999), inexperience (McCartt et al., 2003), and unnecessary risk-taking behaviors (Rolison et al., 2014) have been attributed to collisions involving young drivers. Vehicle collision records have indicated that excessive speed, traffic violations (Gonzales et al., 2005), and reckless driving (Lam, 2003) have been responsible for the collisions. Excessive speed, loss of control, and failure to detect other vehicles or traffic control were reported as the primary causes of collisions involving teenagers (Braitman et al., 2008).

All these findings indicate that inexperience, lack of skill, and risktaking behaviors of young drivers cause collisions. Alcohol use is also one of the most important personal risk factors that cause serious and fatal injuries from accidents and is responsible for approximately one third of all accidentrelated deaths (Zeckey et al., 2011). Nonuse of motorcycle helmets, seatbelts, and child restraints; unsafe road infrastructure (Rolison et al., 2018), distracted driving, unsafe vehicles, and inadequate enforcement of traffic laws are also major causes of road accidents (WHO, 2015).

In one of their studies, Kumarage et al. (2000) found that the geographic location; road geometry features; environmental conditions, and the vehicle condition are also key attributes leading to road accidents. Several key research studies revealed that poor visual functions and poor cognitive abilities of older drivers also cause road traffic collisions (Ball et al., 2010). Medical conditions, such as heart disease and stroke, also contribute to an increased risk of collisions involving older drivers (McGwin et al., 2000; Anstey et al., 2005). Psychoactive medications commonly used by older drivers can also hamper their driving ability and place them at an increased risk of getting involved in road accidents (Meuleners et al., 2011). Thus, road safety management has become a crucial requirement.

\subsection{Road safety management strategies}

Road safety strategies choose, guide, and describe the actions that will reduce the burdens of injuries caused by road accidents (Hughes et al., 2015). They focus on the road users, vehicles, roads, and socio-economic factors (Haddon, 1980). Recently, road safety strategies have been a safe system approach (ITF, 2008). Enacting and enforcing legislation on key behavioral risk factors, including speed; drink-driving; and failure to use motorcycle helmets, seatbelts, and child restraints are critical components of an integrated strategy that will prevent road traffic deaths (WHO, 2018). With more and more countries currently making many efforts to improve their road safety situations (WHO, 2018), a growing need exists for each of these countries to evaluate its own road safety performance 
and compare it with those of other countries (Shen et al., 2020). Road network structures are considered significant for determining traffic safety, especially that of pedestrians (Zhang et al., 2015). Weerasekara (2009) has proposed a road safety plan for Sri Lanka to reduce all serious road casualties, targeting three vital areas: road user behavior, vehicle standards, and road conditions. Safety measures, such as wearing of seat belts and helmets; standards of the vehicles; and conditions of the roads are strategies imperative for improving road safety (WHO, 2019).

According to Lakmal et al. (2020), the Government of Sri Lanka has recently enacted legislation to improve the safety standards of imported motor vehicles. Galgamuwa et al. (2016) suggested a driving cycle for Colombo to reduce the number of entry points. In long crosswalks, a short green time makes pedestrians to hurry and unexpectedly change their walking speed ignoring the surroundings (Alhajyaseen \& IryoAsano, 2017). A well-organized system of road safety equipped with the right structures and procedures can help reduce the risks of road use (Jamroz et al., 2014).

\section{Methodology}

According to McCusker \& Gunaydin (2015), a qualitative approach typically attempted to answer questions starting with 'what', 'how' or 'why', rather than 'how many' or 'how much', which can be answered through a quantitative approach. Creswell (2014) found that a qualitative research approach is the best for collecting opinions and facts from people based on their experiences and behavior. Moreover, such an approach will make the researcher to experience the reality as others do (Ritchie et al., 2014) and help a person to stay close to the empirical world (Taylor et al., 2015). As the aim of the study is to improve the road safety standards in Sri Lanka, the interpretation and contextualization of the collected data were necessary. Thus, a qualitative research approach was employed in the study.

\subsection{Case study with non- participant observations}

Cronin (2014) explained that a case study is a form of qualitative analysis that provides vigilant and comprehensive observations about a situation, an individual, or an institution. Thus, in this study, three roads were selected as the cases and were observed to analyze their road safety conditions. In selecting these three roads, the prevailing road safety facilities, area the road covers, maintenance level, and traffic condition of the roads were considered. Then the observations were made as follows. Firstly, high-traffic zones of the roads were identified by observing the roads during peak hours.

Thereafter, four observation time slots were set per day during peak hours. Each time slot was two hours and were set at different intervals during peak hours on weekdays. Table 1 provides a summary of the key highlights of the observations. The findings were later validated through expert interviews. These findings are explained in the section on discussion.

\subsection{Expert interviews}

Fellows \& Liu (2015) mentioned that expert interviews are best suited to collect data using the experience of the interviewees. 
Table 1: Details of the cases and interviewees

\begin{tabular}{|c|c|}
\hline \multicolumn{2}{|c|}{ Details of the Cases } \\
\hline Type and Name of the Road & Remarks \\
\hline $\begin{array}{l}\text { Galle Road from Galle Face to Panadura } \\
\text { (Bus Route 100) }\end{array}$ & $\begin{array}{l}\text { - A main road with two lanes in each } \\
\text { direction } \\
\text { - A major road in Sri Lanka } \\
\text { - Has undergone several modifications }\end{array}$ \\
\hline $\begin{array}{l}\text { Kottawa - Piliyandala Road } \\
\text { (Bus Route 255) }\end{array}$ & $\begin{array}{l}\text { - A busy two-lane road with no sidewalks or } \\
\text { cycle lanes } \\
\text { - Lacks most of the required safety features }\end{array}$ \\
\hline $\begin{array}{l}\text { Piliyandala - Katubedda Road (Bus } \\
\text { Route 255) }\end{array}$ & $\begin{array}{l}\text { - A newly renovated and expanded road with } \\
\text { proper road signs and many crossings } \\
\text { - Has cycle lanes } \\
\text { - Has no proper sidewalks }\end{array}$ \\
\hline \multicolumn{2}{|c|}{ Details of the Interviewees } \\
\hline Category & Experience in Years \\
\hline $\begin{array}{l}\text { Superintendents of Police } \\
(2 \text { interviewees })\end{array}$ & $20-30$ \\
\hline $\begin{array}{l}\text { Officers in Charge of Traffic } \\
(5 \text { interviewees })\end{array}$ & $10-15$ \\
\hline $\begin{array}{l}\text { Professors } \\
(3 \text { interviewees })\end{array}$ & $15-20$ \\
\hline $\begin{array}{l}\text { Pedestrians } \\
(5 \text { interviewees })\end{array}$ & $10-15$ \\
\hline $\begin{array}{l}\text { Drivers } \\
(5 \text { interviewees })\end{array}$ & $10-15$ \\
\hline
\end{tabular}

As Du Toit \& Mouton (2013) stated, these interviews help to verify whether the views expressed by the interviewees tally with the literature findings. According to Bryman (2017), semistructured interviews allow a researcher to comprehend and explore new ways of seeing the topic of his/her study.

Therefore, considering the nature of the study and the appropriateness of semistructured interviews for it, semistructured interviews were conducted among industry experts and road users, whose details are given in Table 1 .
The interviewees who had to have experience in road safety sector was selected using purposive sampling and were interviewed to obtain an in-depth understanding of the research phenomenon. The sample size complied with the size suggested by Mason (2010)

In selecting the interviewees, priority was given to those who had industry experience, knowledge of the world standards on road safety, and familiarity with the road conditions in Sri Lanka. Two superintendents of police with 20 30 years of experience, ten traffic officers in charge with 10-15 years of experience, 
and 3 professors with 10-15 years of experience in the road management and town planning sector were selected as the expert interviewees. Determining the perspectives of the road users was paramount to comprehend how they perceive road-related activities. Thus, five pedestrians and five drivers were randomly selected and interviewed. The number of cases were limited to three and the number of interviews were limited to 20. This was to avoid data saturation (Saunders et al., 2018). According to Lune \& Berg (2016), content analysis helps to categorize, summarize, and tabulate data, content analysis was used to analyze the collected data manually.

\subsection{Documentary review}

As Shen et al. (2020) explained, to enhance the road safety of a country, the country has to evaluate its road safety performance and compare it with those of other countries. Therefore, a documentary review was conducted to understand the rules, regulations, and good practices associated with the road safety of other countries. The statistics relating to roads in Sri Lanka were analyzed to identify the causes of roadrelated accidents. The causes were then validated at the interviews. The following documents were studied with regard to road traffic rules and pedestrian safety.

- Data on road traffic accidents extracted from Department of Census and Statistics, Sri Lanka (2018)
- Highway Code of Sri Lanka (Extracted from the Motor Traffic Act Chapter 203. (2014)

- UK Highway Code (2019)

- Singapore Highway Code (2020)

- Motor Traffic Act of Sri Lanka and its amendments (2017)

\subsection{Research process}

Figure 1 depicts the research process adopted to achieve the objectives of the study. A preliminary review of the previous studies was first carried out to determine the research gap. An extensive literature survey was thereafter conducted to understand the road safety background in Sri Lanka.

The objectives were then formulated to achieve the research aim of improving the road safety standards in Sri Lanka. The literature survey was conducted to identify the road safety measures adopted in both developing and developed countries. Several causes of road accidents were also identified from the literature. They were later validated through expert interviews and observations. In addition, several sound practices related to road safety were identified through the literature survey.

A comprehensive non- participant observation of three main roads in Sri Lanka was also made as stipulated in section 3.1. This is to examine and understand the causes of road accidents and determine the road safety conditions prevailing in Sri Lanka. 


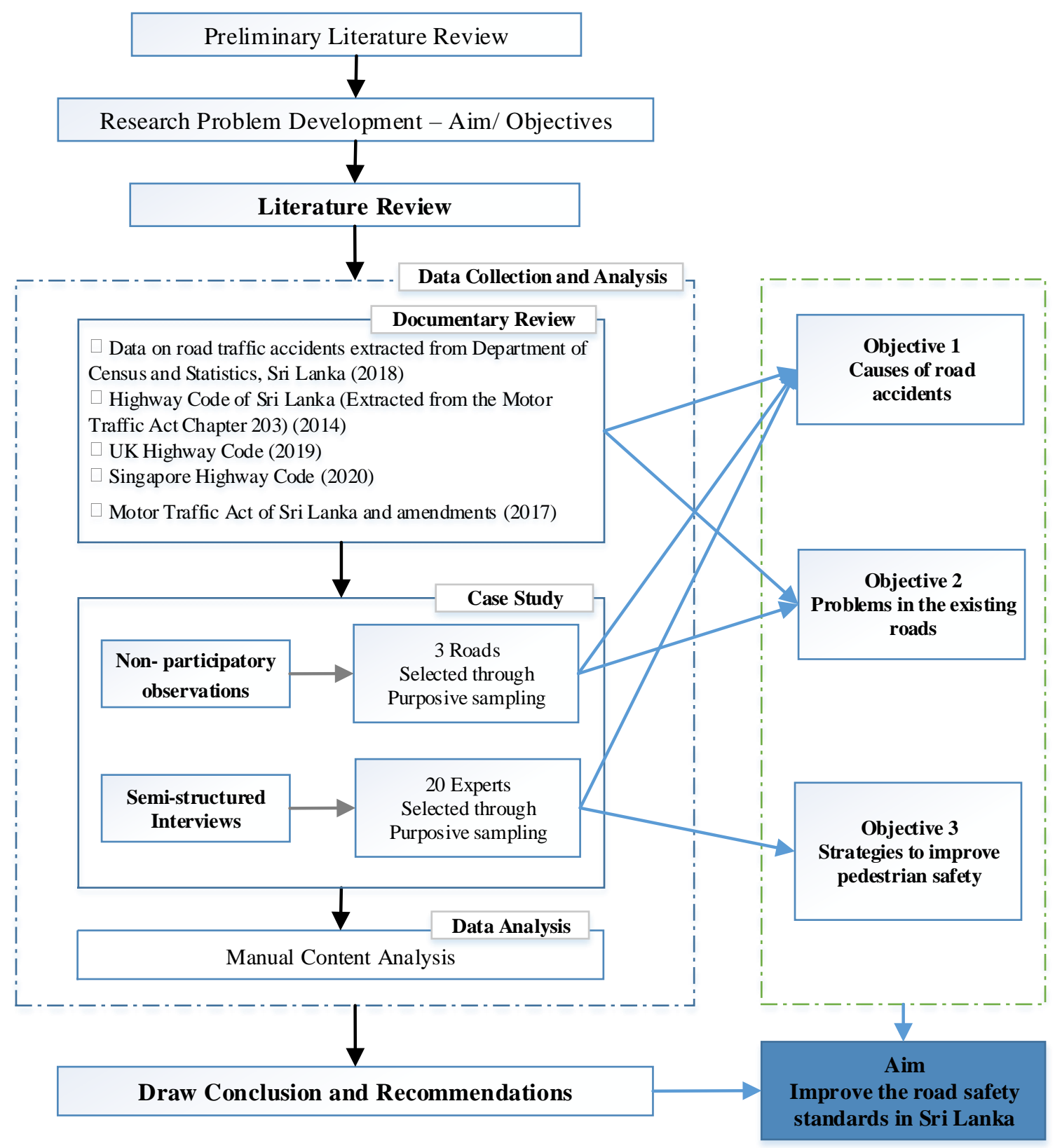

Figure 1: Research process

After making the observations and conducting the documentary reviews, the causes of road accidents in developing countries were identified taking Sri Lanka as an example. Finally, several strategies that could be adopted to enhance the existing road safety conditions were determined based on the sound practices identified from the literature and expert interviews.

\section{Research Findings}

\subsection{Causes of road traffic accidents in Sri Lanka}

Identifying the root causes of road accidents is fundamental to develop the strategies that will enhance road safety in Sri Lanka. Thus, by referring to the literature, several causes of road accidents were identified. Later, they 
were verified by observing the road safety measures currently been adopted and conducting discussions with the experts in the road safety sector.

Table 2 presents the identified causes of road accidents. A ' $\checkmark$ ' mark indicates the source that helped to find the relevant cause and the causes in bold text are the causes suggested by the experts at the interviews. A leading factor influencing road accidents in Sri Lanka is the excessive speeds at which motorists drive their vehicles. As revealed by WHO (2020), every $1 \%$ increase in the mean speed produces a $4 \%$ increase in the fatal crash risk. Bucsuházy et al. (2020) stated that risky overtaking is a key cause of road accidents.
According to the experts who were interviewed, excessive speed and risky overtaking are the two most common causes of the road accidents in Sri Lanka. During the period from 2002 to 2015, the highest number of pedestrian deaths occurred due to the high speed. According to the data available with the Sri Lanka Police, the number of deaths due to risky overtaking was in the range 300 - 500 during $2002-2014$.

However, Rezagholipour et al., (2016) argued that risky overtaking was caused by road inefficiencies, which compel the drivers to engage in perilous overtaking. Singh et al. (2016) found that improper turning of vehicles was a significant reason for road traffic accidents.

Table 2: Causes of road accidents

\begin{tabular}{|l|c|c|c|}
\hline \multicolumn{1}{|c|}{ Cause } & $\begin{array}{c}\text { Documentary } \\
\text { Review }\end{array}$ & $\begin{array}{c}\text { Case } \\
\text { Study }\end{array}$ & $\begin{array}{c}\text { Expert } \\
\text { Interviews }\end{array}$ \\
\hline High speed & $\checkmark$ & & $\checkmark$ \\
\hline Risky overtaking & $\checkmark$ & & $\checkmark$ \\
\hline Improper turning & $\checkmark$ & & $\checkmark$ \\
\hline Intoxication & $\checkmark$ & & $\checkmark$ \\
\hline Carelessness of the pedestrians & $\checkmark$ & & $\checkmark$ \\
\hline Lack of experience in the drivers & $\checkmark$ & $\checkmark$ & $\checkmark$ \\
\hline Unsafe road infrastructure & $\checkmark$ & & $\checkmark$ \\
\hline $\begin{array}{l}\text { Non-use of motorcycle helmets, } \\
\text { seatbelts, and child restraints }\end{array}$ & $\checkmark$ & & $\checkmark$ \\
\hline Fatigue & $\checkmark$ & & $\checkmark$ \\
\hline Weather conditions & $\checkmark$ & & $\checkmark$ \\
\hline Disobeying of road rules & $\checkmark$ & & $\checkmark$ \\
\hline Distractions during driving & $\checkmark$ & & $\checkmark$ \\
\hline Inadequate enforcement of traffic laws & $\checkmark$ & & $\checkmark$ \\
\hline Inadequate post-crash care & $\checkmark$ & & $\checkmark$ \\
\hline Unsafe vehicles & & & $\checkmark$ \\
\hline $\begin{array}{l}\text { Poor driver awareness about road } \\
\text { rules }\end{array}$ & & & $\checkmark$ \\
\hline Unattended minors on the road & & & $\checkmark$ \\
\hline $\begin{array}{l}\text { Poorly designed roads of upcountry } \\
\text { areas }\end{array}$ & & & \\
\hline
\end{tabular}


At the interviews, the experts stated that despite the rules and regulations, drivers prefer to turn at places convenient for them, violating the regulations and ending up in catastrophic accidents. Lack of experience of the drivers is another reason that influences the road-related accidents.

Many of the interviewees claimed that a considerable number of drivers who were at fault were fairly young. Also, they have had a little experience in driving automobiles, which confirmed the findings of Rolison et al. (2018). Road structure is important for road safety according to the literature. Since the design of a road can have a considerable impact on the safety of its users, roads should be designed with the safety of all road users in mind (WHO, 2020). Fatigue and stress also influence road traffic accidents. The police officials who were interviewed mentioned that some of the drivers involved in road accidents have had inadequate sleep or rest. Bucsuházy et al. (2020) also discovered that inadequate sleep or rest can make drivers prone to accidents. Weather conditions too can cause road-related accidents. Distractions that drivers encounter while driving are becoming common and are having an increasing effect on road traffic accidents.

Many studies have established a direct correlation between the distractions and driver inattention. Several experts of the road safety sector confirmed at the interviews that this phenomenon is commonly observed with modern digital electronic equipment i.e., use of mobile phones while driving. Amarasinghe \& Dharmaratne (2019) pointed out that, in Sri Lanka, violating rules, especially at roundabouts, intersections, entrances, byroads, railway crossings, and junctions could be the cause of fatal road traffic accidents. Failure to enforce road rules can also increase road accidents mainly because road users tend to forget the seriousness and importance of the rules. The WHO (2020) in one of its studies has proven that the proper enforcement of rules and regulations could significantly reduce the number of accidents that can occur. Even though the lack of post-crash care does not directly influence road accidents, the failure to provide the required care to accident victims soon after the accident, increases the severity of it. The treatment of the injuries is extremely time sensitive. A delay of even one minute can be the difference between life and death (WHO, 2020).

Non-use of seat belts, helmets, and child constraints is another major cause of road-related accidents. Proper helmet use can lead to a $42 \%$ reduction in the number of accidents that cause fatal injuries and a $69 \%$ reduction in the number of accidents that cause head injuries. By wearing a seat belt, the risk of death of the drivers and front-seat occupants could be reduced by $45-50 \%$ and the risk of death and serious injuries of the rear-seat occupants by $25 \%$, while the use of child restraints can lead to a $60 \%$ reduction in the deaths of children (WHO, 2019). Unsafe vehicle usage is another cause of increased road accidents and deaths, especially in countries like Sri Lanka. While confirming the literature review findings, the interviewees emphasized that, people tend to purchase vehicles without paying attention to the safety standards of the vehicles, because of the economic constraints. According to the interviewees, drivers' lack of knowledge and awareness of the road rules is a cause of accidents, because the drivers will then 
have a higher tendency to violate the rules. Unattended children on roadsides, especially in highly populated city areas, also pose a considerable risk.

\subsection{Problems in the existing roads in Sri Lanka}

To identify the problems associated with the existing roads that make them unsafe for road users, below case studies were selected in Colombo District: Galle Road from Galle Face to Panadura, Kottawa Piliyandala Road, and Piliyandala Katubedda Road. According to the National Transportation Library US (2010), a proper sidewalk is $3.1 \mathrm{~m}$ (10 feet) in length and consists of four zones such as curb zone, planter/furniture zone, pedestrian zone, and frontage zone. However, field observations of the selected roads indicated that sidewalks or pedestrian pavements have not been provided in some parts of these roads as shown on the left side of Figure 2. Pedestrians are compelled to walk at the sides of the road to avoid vehicles and the drains at either side of the roads. This makes it unsafe and risky for the pedestrians. Some parts of Piliyandala Kottawa Road were observed with no sidewalks and wrongly designed bus stops. This can pose a direct threat to the pedestrians. The probability of injuries from oncoming traffic will then be high. In such circumstances, the motorists are also under pressure because they need to provide room to pedestrians while maintaining a safe distance from the other vehicles on the road.

Well-designed bus stops should be constructed away from the main road to avoid any hindrance to the moving vehicles on the road. As shown on the right side of Figure 2, several bus stops had their bus parking demarcations within the road. The bus drivers tended to stop their buses right in the middle of the road to pick up passengers blocking vehicles that were behind. Such situations create unnecessary traffic and increase the chances of vehicle collisions as the vehicles following the bus may not expect the bus to stop to pick up passengers.

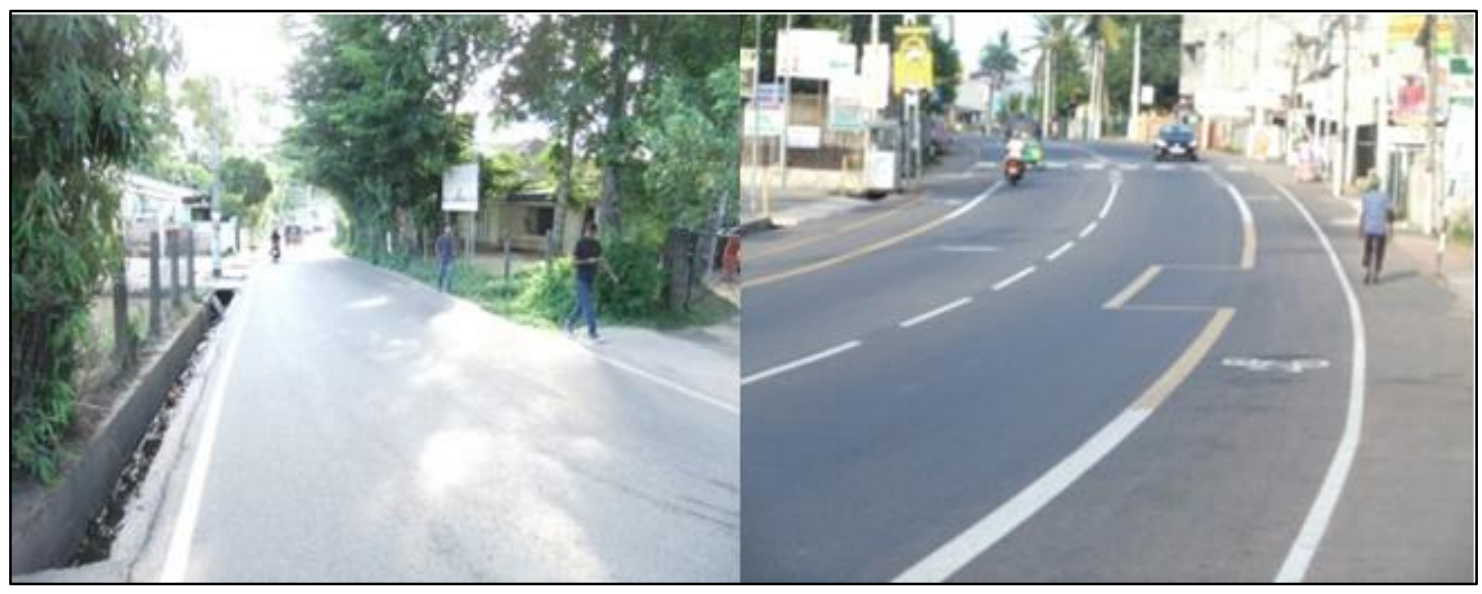

Figure 2: Roads with no sidewalks and wrongly designed bus stop Source: Public Domain 
Accordingly, such situations can cause accidents to both the passengers and motorists. In the observed roads, certain passages had no proper pedestrian road crossings. In the absence of road crossings, the pedestrians find it difficult and hazardous to cross the road amidst of ongoing traffic because incoming vehicles will not slow down. The pedestrians were observed standing right in the middle of the road after crossing the road halfway and wait for the other half of the road to get cleared, thereby facing the risk of being hit by a fast-moving vehicle. Malfunctioning or defective road safety equipment were observed on several occasions at busy intersections in highly commercialized areas. Nonfunctioning traffic lights and indicator buttons were observed at road crossings even in highly populated areas, such as Colombo.

The absence of traffic lights altogether or defective traffic lights were a key shortcoming observed in several roads. As shown on the left of Figure 3, several busy intersections and roads had no traffic signs at all. In the absence of traffic signs, motorists tend to move as they wish. The pedestrians also walk and cross the roads with no guidance. In such places everyone is at risk as they assume that others will always stop for them. Maintenance work was being carried out unsafely without proper preparations or appropriate notifications. Whenever a road renovation or a modification is to be carried out, the relevant authority should take required measures to ensure the safety of both the road users and workers. The Highway Code UK (2019) clearly states in its guidelines, how to carry out roadside work in a live street. Proper safety barricades, traffic divergence mechanisms, and safety demarcations should be provided to ensure the safety of the road users. Many road sections were observed without even a basic demarcation.

A common observation was that the sidewalks were being blocked and disturbed by various activities, thereby neglecting the very purpose of the sidewalks. Name boards were displayed in sidewalks completely preventing the pedestrians from using the sidewalks (Figure 4).

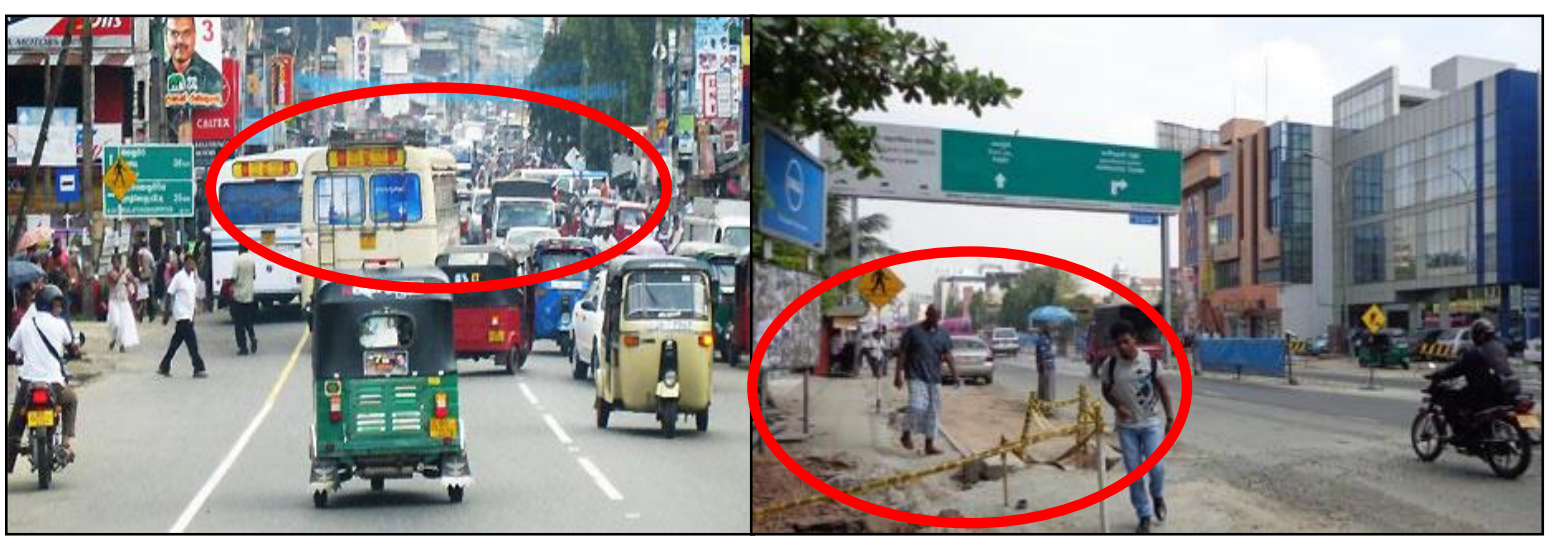

Figure 3: Unsafe intersections with no traffic signs Source: Public Domain 
Concrete lamp posts were right at the middle of pedestrian sidewalks as shown in Figure 4. In the absence of parking facilities, many vehicles were seen parked on the pedestrian walkways. Even though the Motor Traffic Act (chapter 203) clearly prohibits vehicle parking on sidewalks, the rule was not being properly enforced.

Vehicles parked at the roadsides could completely block the sidewalks compelling the pedestrians to walk very close to the moving vehicles. Although Edquist et al. (2012) proved that road siding parking was directly linked with road-related accidents because drivers tend to get disturbed and distracted, no actions were being taken against unlawfully parked vehicles in observed roads.

The case study observations indicated various inadequacies in the roads. According to the guidelines for road facilities, the roads in Sri Lanka need improvements. The absence of basic road safety and pedestrian facilities, such as sidewalks and pavement; defective road safety equipment; wrongly designed road features; unsafe road maintenance activities; and insufficient road crossings at busy intersections were some of the noticeable shortcomings of the observed roads.

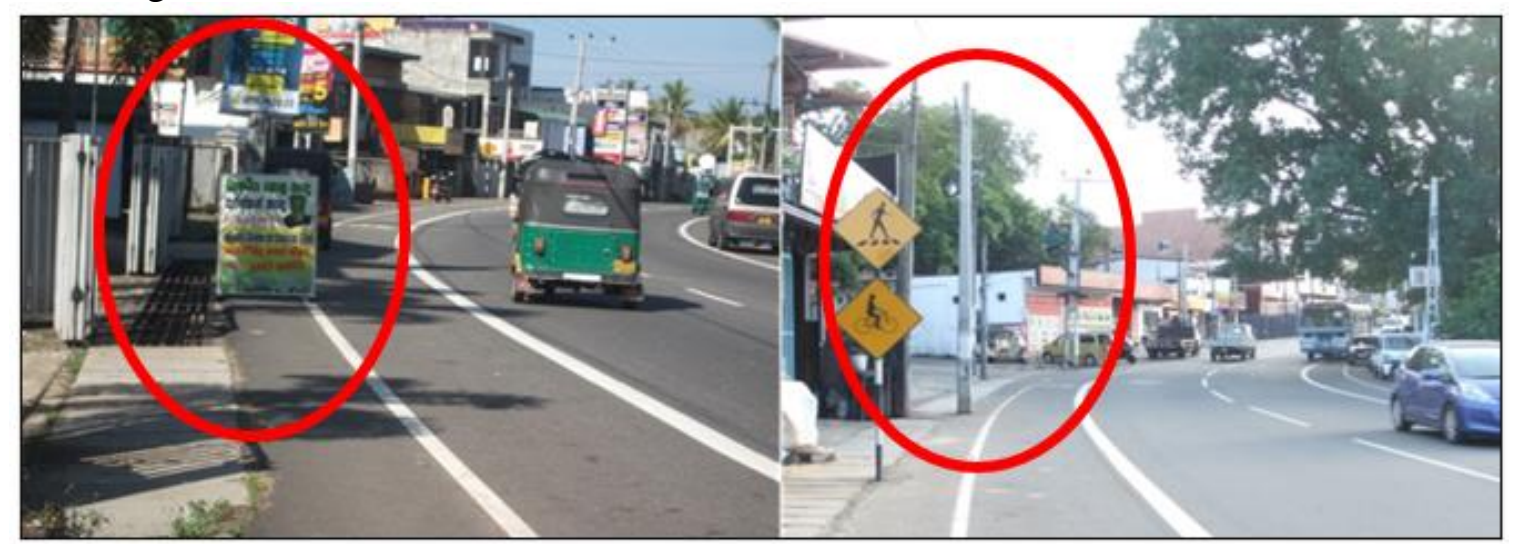

Figure 4: A sidewalk blocked by display boards and lamp posts Source: Public Domain

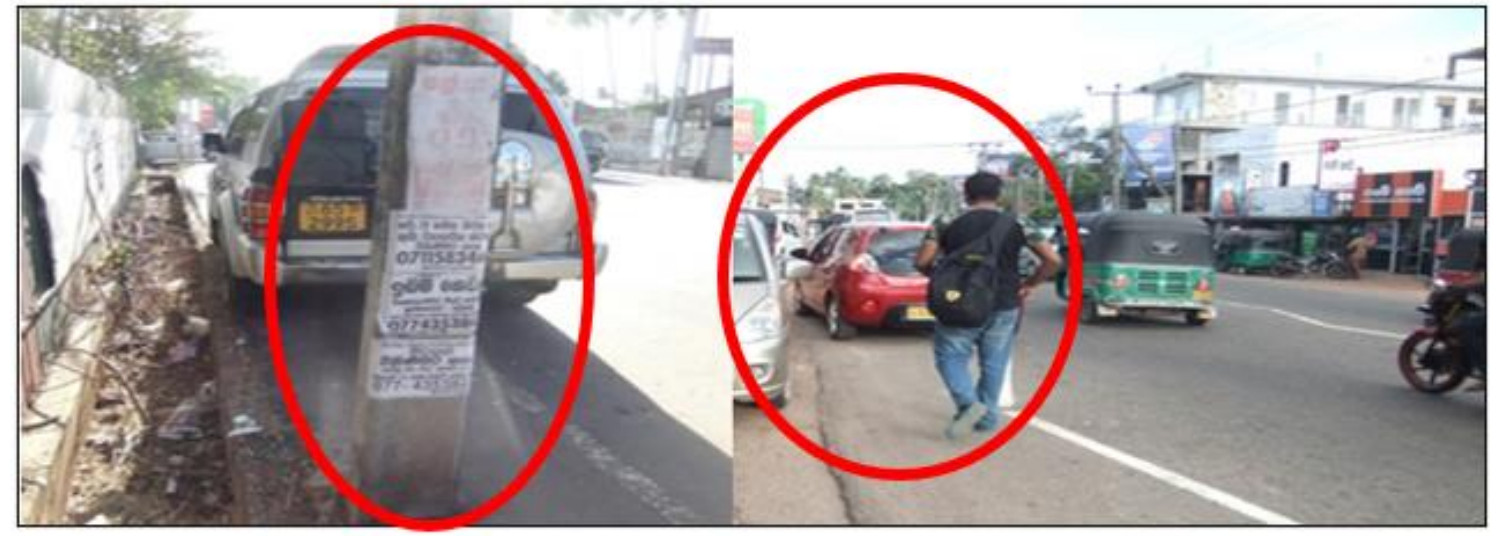

Figure 5: A sidewalk at Piliyandala - Katubedda Road blocked by parked vehicles and lamp posts. Source: Public Domain 


\subsection{Measures that can improve pedestrian safety in Sri Lanka}

The aim of the study is to enhance the road safety in Sri Lanka. The strategies that can improve pedestrian safety in Sri Lanka are listed in Table 3. They were identified by reviewing the literature; observing the road conditions of the country and road safety measures already adopted; and interviewing the experts in the sector. The strategies that are in bold text were suggested by the experts.

As pointed out by Matírnez et al. (2013) and endorsed by the interviewees, excessive speed is the main cause of accidents. The interviewees suggested promoting speed reduction by enforcing tougher rules on speed violations, displaying speed limits more clearly, and monitoring speed violations rigorously.

Table 3: Strategies that can enhance pedestrian safety

\begin{tabular}{|l|c|c|c|}
\hline \multicolumn{1}{|c|}{ Strategies } & $\begin{array}{c}\text { Documentary } \\
\text { Review }\end{array}$ & Case Study & $\begin{array}{c}\text { Expert } \\
\text { Interviews }\end{array}$ \\
\hline $\begin{array}{l}\text { Reducing the maximum allowable } \\
\text { vehicular speed }\end{array}$ & $\checkmark$ & $\checkmark$ & $\checkmark$ \\
\hline Improving the existing road structure & $\checkmark$ & $\checkmark$ & $\checkmark$ \\
\hline Increasing vehicle safety & $\checkmark$ & & $\checkmark$ \\
\hline Installing traffic calming devices & $\checkmark$ & $\checkmark$ & $\checkmark$ \\
\hline Improving the sidewalks & $\checkmark$ & & $\checkmark$ \\
\hline $\begin{array}{l}\text { Increasing the awareness on road traffic } \\
\text { rules }\end{array}$ & $\checkmark$ & $\checkmark$ & $\checkmark$ \\
\hline Improving the crossings & $\checkmark$ & & $\checkmark$ \\
\hline Conducting periodic vehicle inspections & $\checkmark$ & & $\checkmark$ \\
\hline $\begin{array}{l}\text { Developing a national strategy on road } \\
\text { safety }\end{array}$ & $\checkmark$ & & $\checkmark$ \\
\hline $\begin{array}{l}\text { Encouraging scientific research on road } \\
\text { safety management }\end{array}$ & $\checkmark$ & & $\checkmark$ \\
\hline Enacting new legislation & $\checkmark$ & $\checkmark$ & $\checkmark$ \\
\hline $\begin{array}{l}\text { Introducing specially designed streets for } \\
\text { the pedestrians }\end{array}$ & $\checkmark$ & & $\checkmark$ \\
\hline Providing education and information & & $\checkmark$ & $\checkmark$ \\
\hline Carrying out regular maintenance of roads & & & $\checkmark$ \\
\hline Providing seating / shading facilities & $\checkmark$ & & $\checkmark$ \\
\hline $\begin{array}{l}\text { Strictly implementing road rules and } \\
\text { offering an incentive scheme for police } \\
\text { officers }\end{array}$ & & & $\checkmark$ \\
\hline $\begin{array}{l}\text { Implementing a structured process for } \\
\text { issuing driving licenses }\end{array}$ & & & $\checkmark$ \\
\hline $\begin{array}{l}\text { Implementing a comprehensive license } \\
\text { renewal process }\end{array}$ & & & \\
\hline $\begin{array}{l}\text { Getting professionals to carefully design } \\
\text { the roads in upcountry areas }\end{array}$ & & & \\
\hline
\end{tabular}


According to WHO (2020), setting and enforcing speed limits are two of the most effective measures that would reduce road traffic injuries. The interviewees stated that it was imperative to identify the high-risk zones, such as schools, hospitals, supermarkets, and residential areas, and clearly display traffic signs in those areas indicating the maximum allowed speeds, especially in areas where no barricades have been provided to protect the walking paths or pavements. A suggestion was made to introduce "Traffic Calming Devices" such as raised crosswalks, speed bumps, and 3D paintings on the roads to reduce vehicular speeds as done in other countries.

A well-structured and well-maintained road system is paramount for enhancing road safety. A study carried out in Chile by Sánchez-González et al. (2021) also indicated that investments on road safety have a direct influence on reducing road related accidents. According to Schermers (1999) and Peden et al. (2004), and the interviewees, the improvement of the existing road structure will considerably reduce road accidents and pedestrian fatalities. For example, Karunarathne et al. (2019) found out that in a country like Sri Lanka, roundabouts, being heterogeneous, do not serve their intended purpose.

The interviewees also indicated that damaged road surfaces, narrow road passages, and dangerous bends have a direct impact on road traffic accidents as motorists find it difficult to control their vehicles under those circumstances. As explained by Tsukaguchi (2019), lack of appropriate signs in pedestrian-intensive areas creates issues. Thus, the entire road network must be studied to identify the critical points that can cause pedestrian deaths. Improving the existing road network with proper alterations is, therefore, paramount to enhance road safety.

As per the experts, although a large number of marked road crossings are provided in the road network in Sri Lanka, they need critical improvements. As stated by Peden et al. (2004), the improvement and upgrading of pedestrian crossings can be considered a 'good practice' to reduce the number of road-related accidents.

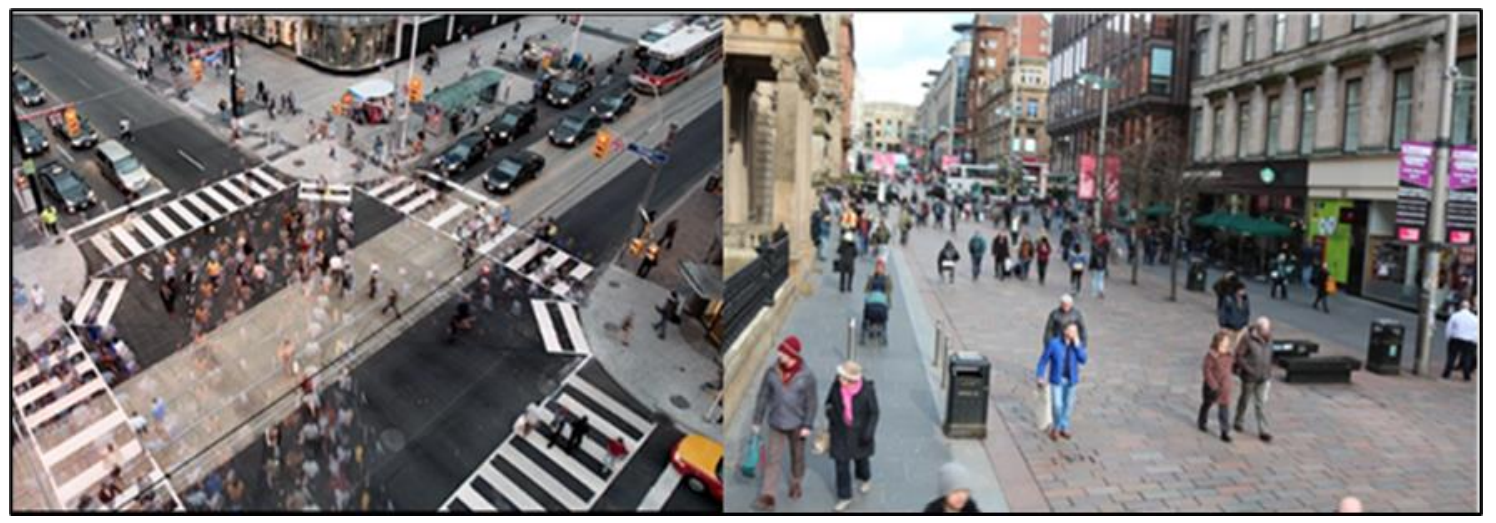

Figure 6: An exclusive pedestrian phase provided at a junction and a road designated only for pedestrians Source: Public Domain 
The interviewees stated that if crossings are provided at busy intersections where pedestrian density and traffic flow are considerably high, the risk of pedestrians crossing the road would also be high. In such locations, an exclusive pedestrian phase can be created where vehicles from all directions will have to stop to enable pedestrians to cross the road even diagonally as shown in Figure 6.

In several other countries, designated streets for pedestrians have been provided as shown in Figure 6, to reduce road traffic accidents and vehicular traffic. According to the literature, sidewalks have assisted in reducing the number of accidents globally. Properly designed sidewalks at either side of a road improve pedestrian safety.

During field observations, it was noticed that certain areas on the Kottawa Piliyandala Road are not provided with well-designed sidewalks, thereby placing both pedestrians and drivers at risk. The interviewees also believed that the absence of safety features has directly and adversely influenced road safety. One key point highlighted by the interviewees was the lack of awareness of the public about road rules and regulations. Getting the attention of the public on the best practices of road usage and making them aware about the possible road injuries would help to reduce road-related accidents.

Campaigns, school-based programs, and awareness programs meant for the entire public would be beneficial. However, Hoekstra \& Wegman (2011) argued that before conducting campaigns on road safety, the effectiveness of those campaigns should be critically analyzed. If the correct practices are not promoted through the campaigns, their purpose would be lost, while road safety would also be negatively affected.

The introduction of new laws on road safety is crucial for a country like Sri Lanka. Policymakers need to learn and develop the existing road safety framework employing the best practices, especially when the overall road safety is unsatisfactory. While stressing this point, Western Megapolis Project (2019) plans introduced new laws to strictly implement road safety regulations, and to provide programs for drivers to inculcate a disciplined driving culture.

The learning and knowledge gathered should be demonstrated subsequently through the legal framework of the country. As Goniewicz et al. (2015) explained and endorsed by the interviewees, proper legislation may also be effective in eliminating the risky road user behaviors, and in increasing road safety.

The expert interviewees suggested to introduce new laws pertaining to road traffic to control traffic violations and create awareness among the road users. As mentioned by the WHO (2020), Sri Lanka currently does not have in place a national strategy for road safety management. Countries that maintain high road safety standards have such national strategies in place.

As indicated by the experts, a comprehensive road safety management strategy would directly enhance the road safety standards in the country and benchmark the practices followed in the country with the 'best practices' followed elsewhere. Additionally, in Sri Lanka, the lack of road safety research, limited 
availability of statistics on road traffic crashes and injuries makes it difficult for the policymakers to propose interventions that would prevent road traffic crashes (Dharmaratne et al., 2015). Thus, a proper research-based analysis is vital for enhancing the road safety standards of the country.

Road defects can cause serious injuries to motorists, while uncontrollable vehicles can cause injuries to pedestrians. Therefore, the authorities may have to ensure that periodic road maintenance is carried out to maintain the quality and the standards of the roads.

Continuous education and information sharing would help to reduce the number of road- related accidents. The mistakes committed by road users can be reduced by educating them on road traffic safety through educational programs and skill training. Refresher courses could be organized for older drivers. Such programs would change the behaviors of the road users and increase their awareness on road safety (WHO, 2004). Several scholars, including Wegman (2016) have pointed out the importance of continuously increasing the safety levels of vehicles to reduce road-related accidents. The mandatory periodic maintenance of vehicles will keep the vehicles well-tuned and seasoned. Accordingly, in an emergency, the drivers would be able to manage the situation using the basic technical functions available in the vehicles.

The interviewees were of the view that the driving license issuing process in Sri Lanka could be improved by getting the prospective drivers to attend a compulsory training program and/or a workshop through which their knowledge on road rules and regulations could be improved.

The renewal of the licenses could be done only after ascertaining that the drivers are aware of the new developments in road rules. Special attention has to be paid when designing the roads in upcountry areas because of their susceptibility to landslides and other natural disasters. Finally, the interviewees suggested introducing an incentive system for traffic police officers to improve the implementation of road rules.

\section{Conclusions}

Developing countries, such as Sri Lanka, have to suffer both economically and socially because of the increasing number of road traffic accidents. The failure to ensure road safety and the limited number of past studies conducted on the subject indirectly aggravate the complexity of the problem. The findings of this study reveal that the road conditions in the country are unsatisfactory, and that the road system of the country has several defects and inefficiencies.

Going by the global road standards and guidelines, the studied roads displayed several basic deficiencies. Lack of road safety measures, such as improperly designed sidewalks and defective traffic equipment were common in the observed roads. All the cases examined, i.e., Galle Road, Piliyandala-Katubedda Road and Kottawa-Piliyandala Road, required improvements to meet global standards.

The study revealed several factors that cause road accidents. High speeds, risky overtaking, improper turning, intoxication, carelessness of the pedestrians, lack of experience in the 
drivers, unsafe road infrastructure, and non-use of safety features are few of the identified causes. The causes of road accidents were first identified from the literature and were subsequently validated through the interviews. The case observations revealed that the problems associated with the roads are also responsible for the road accidents. The inefficiencies of the roads also increase the number of traffic accidents. The last objective of the study was achieved by identifying from the literature, nineteen strategies that would minimize the road accidents in the country and validating them through the interviews conducted with industry experts. Strictly enforcing speed laws, improving the existing roads, enacting new laws, conducting periodical vehicle inspections, and encouraging road safety research are some of the key strategies identified.

The study findings would be useful for the Road Development Authority of Sri Lanka; Traffic Administration and Road Safety Division of Sri Lanka Police; and other relevant authorities in the country when planning road safety. Moreover, the causal factors of road accidents can be used as guidelines during policy making and in road safety education. The study findings would also be useful to other developing countries to enhance the road safety in their respective countries.

This study contributes to filling the knowledge gap on the causes of road accidents and the problems associated with the roads in developing countries. The identified strategies that would enhance the road safety in Sri Lanka would provide a basis for the future researchers to conduct further research on the subject. Even though the study cannot be theoretically generalized, its findings could be used as a benchmark for studies in other developing countries. For those developing countries struggling with road safety issues, the study provides a platform to identify the root causes of road accidents and find the required solutions. One limitation of the study was its confinement to Sri Lanka. The relevance of the study findings to other countries will depend on their road infrastructure standards.

\section{References}

Alfonzi, R., Persia, L., Antonino, T. and Usami, D.S. (2016) Advancements in road safety management analysis. Transportation Research Procedia, 14, 2064-2073. https://doi.org/10.1016/j.trpro.2016.05.105

Alhajyaseen, W. K. and IryoAsano, M. (2017) Studying critical pedestrian behavioral changes for the safety assessment at signalized crosswalks. Safety Science, 91, 351-360.

Alhajyaseen, W. K., Asano, M. and Nakamura, H. (2012) Estimation of left-turning vehicle maneuvers for the assessment of pedestrian safety at intersections. IATSS Research, 36, 66-74. https://doi.org/10.1016/j.iatssr.2012.03.002

Amarasinghe, P.G. and Dharmaratne, S.D. (2019) Epidemiology of road traffic crashes reported in the Kurunegala police division in Sri Lanka". Sri Lanka Journal of Medicine, 28(1), 10-19. http://doi.org/10.4038/sljm.v28i1.102 
Anstey, K.J., Wood, J., Lord, S. and Walker, J.G. (2005) Cognitive, sensory, and physical factors enabling driving safety in older adults. Clinical Psychology Review, 25(1), 45-65. https://doi.org/10.1016/j.cpr.2004.07.008

Ball, K., Edwards, J.D., Ross, L.A. \& McGwin, G. (2010) Cognitive training decreases motor vehicle collision involvement of older drivers. Journal of the American Geriatrics Society, 58(11), 2107-2113. https://doi.org/10.1111/j.1532-5415.2010.03138.x

Banerjee, A., \& Maurya, A. K. (2019). Impact of land use type over pedestrian flow characteristics for skywalk facilities in Mumbai, India. Journal of the Eastern Asia Society for Transportation Studies, 13, 1134-1149.

Batishcheva, O. \& Ganichev, A. (2017) Creative approaches to organization and safety of road traffic. Transportation Research Procedia, 20, 36-40. https://doi.org/10.1016/j.trpro.2017.01.008

Bhavan, T. (2019) The economic impact of road accidents: the case of Sri Lanka. South Asia Economic Journal, 20(1), 124-137. https://doi.org/10.1177/1391561418822210

Bishai, D. (2003). Rates of public investment for road safety in developing countries: case studies of Uganda and Pakistan. Health Policy and Planning, 18(2), 232-235. https://doi.org/10.1093/heapol/czg028

Braitman, K.A., Kirley, B.B., McCartt, A.T. \& Chaudhary, N.K. (2008) Crashes of novice teenage drivers: characteristics and contributing factors. Journal of Safety Research, 39(1), 47-54. https://doi.org/10.1016/j.jsr.2007.12.002

Bryman, A. (2017) Social Research Method, 4th ed, Oxford University Press, New York.

Bucsuházy, K., Matuchová, E., Zůvala, R., Moravcová, P., Kostíková, M. \& Mikulec, R. (2020) Human factors contributing to the road traffic accident occurrence, Transportation Research Procedia, 45, 555-561. https://doi.org/10.1016/j.trpro.2020.03.057

Calvo-Poyo, F., Navarro-Moreno, J., \& de Oña, J. (2020). Road Investment and Traffic Safety: An International Study. Sustainability, 12(16), 6332. https://doi.org/10.3390/su12166332

Cookson, R.E., Richards, D.C. \& Cuerden, R.W. (2011) The characteristics of pedestrian road traffic accidents and the resulting injuries. TRL Insight Report INS009, IHS for TRL, Berkshire.

Crandall, J.R., Bhalla, K.S. and Madeley, N.J. (2002) Designing road vehicles for pedestrian protection, $B M J$, 324(7346), 1145-1148. https://doi.org/10.1136/bmj.324.7346.1145

Creswell, J. W. (2014). Research Design: Qualitative, Quantitative and Mixed Methods Approaches (4th ed.). Thousand Oaks, CA: Sage.

Cronin, C. (2014) Using case study research as a rigorous form of inquiry, Nurse Researcher, 21(5), 19-27. https://doi.org/10.7748/nr.21.5.19.e1240

Department of Census and Statistics, Sri Lanka. (2018). Statistical abstract 2018: Chapter vii - transport and communication, Available at http://www.statistics.gov.lk/Abstract2018/index.asp?page=chap7

Dharmaratne, S.D., Jayatilleke, A.U. and Jayatilleke, A.C. (2015) Road traffic crashes, injury and fatality trends in Sri Lanka: 1938-2013. Bulletin of the World Health Organization 2015, 93, pp 640-647. http://dx.doi.org/10.2471/BLT.14.150193

Du Toit, J.L. and Mouton, J. (2013) A typology of designs for social research in the built environment. International Journal of Social Research Methodology, 16(2), pp.125-139. https://doi.org/10.1080/13645579.2012.657013 
Edquist, J., Rudin-Brown, C. M., \& Lenné, M. G. (2012). The effects of on-street parking and road environment visual complexity on travel speed and reaction time. Accident Analysis \& Prevention, 45, 759 765. https://doi.org/10.1016/j.aap.2011.10.001

Eusofe, Z. and Evdorides, H. (2017) Assessment of road safety management at institutional level in Malaysia: A case study, IATSS Research, 41(4), pp. 172-181. https://doi.org/10.1016/j.iatssr.2017.03.002

Fellows, R.F. and Liu, A.M. (2015), Research Methods for Construction, John Wiley \& Sons, Sussex, UK.

Galgamuwa, U., Perera, L., \& Bandara, S. (2016). Development of a driving cycle for Colombo, Sri Lanka: an economical approach for developing countries. Journal of Advanced Transportation, 50(7), 1520-1530.

Goniewicz, K., Goniewicz, M., Pawłowski, W. and Fiedor, P. (2015) Road accident rates: strategies and programmes for improving road traffic safety, European Journal of Trauma and Emergency Surgery, 42(4), pp. 433-438. https://doi.org/10.1007/s00068-015-0544-6

Gonzales, M.M., Dickinson, L.M., DiGuiseppi, L.M. and Lowenstein, S.R. (2005) Student drivers: A study of fatal motor vehicle crashes involving 16-year-old drivers, Annals of Emergency Medicine, 45(2), pp. 140146.

Gopalakrishnan, S. (2012) A public health perspective of road traffic accidents, Journal of Family Medicine and Primary Care, 1(2), pp. 144-150. https://doi.org/10.4103/2249-4863.104987

Haddon, W. (1980) Options for the prevention of motor vehicle crash injury, Israel Journal of Medical Sciences, 16(1), pp. 45-65.

Heydari, S., Hickford, A., McIlroy, R., Turner, J., \& Bachani, A. M. (2019). Road safety in low-income countries: state of knowledge and future directions. Sustainability, 11(22), 6249.

Hoekstra, T. and Wegman, F. (2011) Improving the effectiveness of road safety campaigns: Current and new practices, IATSS Research, 34(2), pp. 80-86. https://doi.org/10.1016/j.iatssr.2011.01.003

Hughes, B.P., Newstead, S., Anund, A., Shu, C.C. and Falkmer, T. (2015) A review of models relevant to road safety, Accident Analysis \& Prevention, 74, pp. 250-270. https://doi.org/10.1016/j.aap.2014.06.003

ITF. (2008) Towards Zero: Ambitious Road Safety Targets and the Safe System Approach, OECD Publishing, Paris, https://doi.org/10.1787/9789282101964-en

Jadaan, K., Al-Braizat, E., Al-Rafayah, S., Gammoh, H., \& Abukahlil, Y., (2018). Traffic Safety in Developed and Developing Countries: A Comparative Analysis. Journal of traffic and Logistics Engineering, 6(1). https://doi.org/10.18178/jtle.6.1.1-5

Jähi, H., Muhlrad, N., Buttler, I., Gitelman, V., Bax, C., Dupont, E., Giustiniani, G., Machata, K., Martensen, H., Papadimitriou, E. and Persia, L., Talbot, R., Vallet, G., Yannis. G. (2012) Investigating road safety management processes in Europe, Procedia-Social and Behavioral Sciences, 48, pp. 2130-2139. https://doi.org/10.1016/j.sbspro.2012.06.1186

Jamroz, K., Budzyński, M., Kustra, W., Michalski, L. and Gaca, S. (2014) Tools for road infrastructure safety management-Polish experiences, Transportation Research Procedia, 3, pp. 730-739. https://doi.org/10.1016/j.trpro.2014.10.052

Jayaratne, M.D.R.P., \& Kumarage, A., S., (2006). Analysis of trends in fatal accidents of vulnerable road users in Sri Lanka. Poland 
Karunarathne, T., Sandaruwan, A., \& Wickramasinghe, V. (2019). Modification of SIDRA model for capacity estimation of urban roundabouts under mixed traffic condition in Sri Lanka. Journal of the Eastern Asia Society for Transportation Studies, 13, 172-186.

Khanal, M., Sarkar, P., (2014). Road Safety in Developing Countries. Journal of Civil \& Environmental Engineering, 2. https://doi.org/10.4172/2165-784X.S2-001

Kumarage, A. S., Abeygoonawardena, C. R., \& Wijesundera, R. (2000). Identifying causal factors of traffic accidents in Sri Lanka. 94 th Annual Sessions, Institution of Engineers, Sri Lanka.

Kumarage, A.S. (2012), Sri Lanka Transport Sector Policy Note, Final Report, World Bank.

Kumarage, A.S., Wickramasinghe, S.M. and Jayaratne, M.D.R.P. (2003) Analysis for Road Accidents in Sri Lanka, Supreme group of Companies, Kelaniya.

Lakmal, M. A. C., Ekanayake, E. M. D. N. K., Kelum, S. H. P., Gamage, B. D., \& Jayasundara, J. A. S. B. (2020). Hospital-based case series analysis of road traffic trauma patients in Sri Lanka. Indian journal of surgery, 1-6.

Lam, L.T. (2003) Factors associated with young drivers' car crash injury: comparisons among learner, provisional, and full licensees, Accident Analysis \& Prevention, 35(6), pp. 913-920. https://doi.org/10.1016/s0001-4575(02)00099-4

Liyanage, P.L.S., \& Santoso, D.S. (2017). Investigating behavior of motorcycle riders from negative experience and profile: A case study of Colombo, Sri Lanka. Journal of the Eastern Asia Society for Transportation Studies, 12, 1857-1870.

Lopez, G., Baena, L., Garach, L. and Ona, J. (2016) Tool to manage road safety deficiencies and risk of highway crashes, Transportation Research Procedia, 18, pp. 272-280. https://doi.org/10.1016/j.trpro.2016.12.041

Lune, H. and Berg, B.L. (2016), Qualitative Research Methods for the Social Sciences. Pearson Higher Ed, New York.

Matírnez, A., Mántaras, D.A. and Luque, P. (2013) Reducing posted speed and perceptual countermeasures to improve safety in road stretches with a high concentration of accidents, Safety Science, 60, pp. 160-168. https://doi.org/10.1016/j.ssci.2013.07.003

McCartt, A.T., Shabanova, V.I. and Leaf, W.A. (2003) Driving experience, crashes and traffic citations of teenage beginning drivers, Accident Analysis \& Prevention, 35(3), pp. 311-320. https://doi.org/10.1016/s0001-4575(02)00006-4.

McCusker, K. and Gunaydin, S. (2015) Research using qualitative, quantitative or mixed methods and choice based on the research, Perfusion, 30(7), pp. 537-542. https://doi.org/10.1177/0267659114559116

McGwin, G. and Brown, D.B. (1999) Characteristics of traffic crashes among young, middle-aged, and older drivers, Accident Analysis \& Prevention, 31(3), pp, 181-198. https://doi.org/10.1016/s0001-4575(98)00061$\underline{X}$

McGwin, G., Sims, R.V., Pulley, L. and Roseman, J.M. (2000) Relations among chronic medical conditions, medications, and automobile crashes in the elderly: A population-based case-control study, American Journal of Epidemiology, 152(5), pp. 424-431. https://doi.org/10.1093/aje/152.5.424

Mason, M. (2010) 'Sample size and saturation in PhD studies using qualitative interviews', Forum Qualitative Sozialforschung, 11(3). doi: 10.17169/fqs-11.3.1428. 
Meuleners, L.B., Duke, J., Lee, A.H., Palamara, P., Hildebrand, J. and Ng, J.Q. (2011) Psychoactive medications and crash involvement requiring hospitalization for older drivers a population-based study, Journal of the American Geriatrics Society, 59(9), pp. 1575-1580. https://doi.org/10.1111/j.15325415.2011.03561.x

Ministry of Megapolis \& Western Development (MMWD). (2016). The Megapolis: western region master plan 2030. Ministry of Megapolis and Western Development. Retrieved from http://www.slembassykorea.com/eng/download/Megapolis\%20Master\%20Plan.pdf

Motor Traffic (Amendment) Act Sri Lanka, No. 18 of 2017, Available at https://www.srilankalaw.lk/gazette/2017_pdf/18-2017_E.pdf

Motor Traffic Act Sri Lanka, c. 203, (2014), Available at http://www.cmta.lk/downloads/Motor\%20Traffic\%20Act\%20-\%20Road\%20Signs.pdf

Nalaka C., Sivakumar, T., (2016), Development of Relationships between Traffic Volume, Number of Accidents and Road Infrastructure Improvements. R4TLI Conference Proceedings

National Transportation Library US (2010). Maintenance of signs and sign supports: a guide for local highway and street maintenance personnel. Retrieved from https://rosap.ntl.bts.gov/view/dot/24522

Papadimitriou, E. and Yannis, G. (2013) Is road safety management linked to road safety performance?, Accident Analysis and Prevention, 59๑, pp. 593-603. http://dx.doi.org/10.1016/j.aap.2013.07.015

Peden, M., Scurfield, R., Sleet, D., Mohan, D., Hyder, A.A., Jarawan, E. and Mathers C. (2004) World Report on Road Traffic Injury Prevention, WHO, Geneva.

Persia, L., Usami, D.S., De Simone, F., De La Beaumelle, V.F., Yannis, G., Laiou, A., Han, S., Machata, K., Pennisi, L., Marchesini, P. and Salathè, M. (2016) Management of road infrastructure safety, Transportation Research Procedia, 14, pp. 3436-3445. https://doi.org/10.1016/j.trpro.2016.05.303

Rezagholipour, K., Massoudian, N. and Eshghi, M. (2016) Modeling and reducing overtaking accidents on two-lane curved road, In 2nd International Conference of Signal Processing and Intelligent Systems (ICSPIS), 14-15 Dec 2016 at, Amirkabir University of Technology, Tehran, Iran. pp. 1-5.

Ritchie, J., Lewis, J., Nicholls, C.M. and Ormston, R. (2014) Qualitative Research Practice: A Guide for Social Science Students and Researchers, Sage, London, UK

WHO (2013) 'Road safety status in the WHO South-East Asia Region, 2013', (1), pp. 1-8.

Road Traffic Act. Chapter 276, Singapore Highway Code 2020, Available at https://sso.agc.gov.sg/SL/RTA1961-R11

Rolison, J. J., Regev, S., Moutari, S. and Feeney, A. (2018) What are the factors that contribute to road accidents? An assessment of law enforcement views, ordinary drivers' opinions, and road accident records, Accident Analysis \& Prevention, 115, pp. 11-24. https://doi.org/10.1016/j.aap.2018.02.025

Rolison, J.J., Hanoch, Y., Wood, S. and Pi-Ju, L. (2014) Risk taking differences across the adult lifespan A question of age and domain, The Journals of Gerontology Series B, Psychological Sciences and Social Sciences, 69, pp. 870-880. https://doi.org/10.1093/geronb/gbt081

Safarpour, H., Khorasani-Zavareh, D., \& Mohammadi, R. (2020). The common road safety approaches: A scoping review and thematic analysis. Chinese Journal of Traumatology. https://doi.org/10.1016/j.cjtee.2020.02.005 
Sakhapov, R. and Nikolaeva, R. (2018), Traffic safety system management, Transportation Research Procedia, 36, pp. 676-681. https://doi.org/10.1016/j.trpro.2018.12.126

Sánchez-González, M.P., Tejada-Ponce, A., Bonnefoy, J., Escribano-Sotos, F. (2021). Regional conditions and road traffic collisions on rural roads in Chile. Journal of Transport \& Health. 20

Saunders, B., Sim, J., Kingstone, T., Baker, S., Waterfield. J., Bartlam. B., Burroughs. H. and Jinks. C. (2018) Saturation in qualitative research: Exploring its conceptualization and operationalization, Quality \& Quantity, 52, pp. 1893-1907. https://doi.org/10.1007/s11135-017-0574-8

Schermers, G. (1999), Sustainable safety: a preventative road safety strategy for the future, AVV Transport Research Centre, Ministry of Transport, Public Works and Water Management.

Shen, Y., Hermans, E., Bao, Q., Brijs, T. and Wets, G. (2020) Towards better road safety management: lessons learned from international benchmarking, Accident Analysis \& Prevention, 138, pp. 105484. https://doi.org/10.1016/j.aap.2020.105484

Shoukrallah, R. (2008) Road safety in five leading countries, Journal of the Australasian College of Road Safety, 19(1), pp 1-12.

Singh, J., Sahni, M.K., Bilquees, S., Khan, S.M.S. and Haq, I. (2016) Reasons for road traffic accidentsvictims' perspective, International Journal of Medical Science and Public Health, 5(4), pp. 814 -818. https://doi.org/10.5455/ijmsph.2016.07112015357

Taylor, S.J., Bogdan, R. and DeVault, M. (2015) Introduction to Qualitative Research Methods: A Guidebook and Resource, John Wiley \& Sons, Sussex, UK.

Tennakoon, V., Wiles, J., Peiris-John, R., Wickremasinghe, R., Kool, B., \& Ameratunga, S. (2020). Transport equity in Sri Lanka: Experiences linked to disability and older age. Journal of Transport \& Health, 18, 100913.

The Highway Code. (2019). Available at www.highwaycodeuk.co.uk

Tsukaguchi, H., Vandebona, U., Nakamura, T., Ahn, Y., Shiomi, Y., (2019). Modelling of Pedestrian Sign Locations in a large Transpotation Hub. Journal of the Eastern Asia Society for Transportation Studies.13

UK Highway Code (2019), Available at https://www.highwaycodeuk.co.uk/uploads/3/2/9/2/3292309/the_official_highway_code_-_20-08-2019.pdf [last accessed 30 June 2021]

UNCTAD (2017) 'TRANSPORT AND Series No 10 Road Safety - Considerations in Support of the 2030 Agenda for Sustainable Development Considerations in Support of the 2030 Agenda for Sustainable Development', (Series No. 10), p. 11. Available at: https://unctad.org/system/files/officialdocument/dtltlb2017d4_en.pdf [last accessed 30 June 2021]

Verzosa, N., \& Miles, R. (2016). Severity of road crashes involving pedestrians in Metro Manila, Philippines. Accident Analysis \& Prevention, 94, 216-226. https://doi:10.1016/j.aap.2016.06.006

Weerasekera, Kolita. (2009). Towards Better Roads,P \& P Associate (Pvt) Ltd., Sri Lanka.

Wegman, F. (2016) The future of road safety: A worldwide perspective, IATSS Research, 40(2), pp. 66-71. https://doi.org/10.1016/j.iatssr.2016.05.003

World Bank. (2020), Delivering Road Safety in Sri Lanka: The Leadership Priorities and Initiatives to 2030, World Bank Publications, Washington. 
World Health Organisation (WHO). (2013), Global Status Report on road safety 2013: Supporting Decade of Actions. WHO Publications, Geneva.

World Health Organisation (WHO). (2017), Road Safety: Basic Facts, Fact Sheet No.1, WHO Publications, Geneva.

World Health Organisation (WHO). (2018) Global Status Report on Road Safety 2018, WHO Publications, Geneva.

World Health Organisation (WHO). (2019) Seat-belts and child restraints: a road safety manual for decisionmakers and practitioners, FIA Foundation for the Automobile and Society, London.

World Health Organisation (WHO). (2020) Road Traffic Injuries, Retrieved from https://www.who.int/newsroom/fact-sheets/detail/road-traffic-injuries.

Zeckey, C., Dannecker, S., Hildebrand, F., Mommsen, P., Scherer, R., Probst, C., et al. (2011) Alcohol and multiple trauma-is there an influence on the outcome? Alcohol, 45, pp. 245-251. https://doi.org/10.1016/j.alcohol.2010.08.004

Zhang, Y., Bigham, J., Ragland, D. and Chen, X. (2015) Investigating the associations between road network structure and non-motorist accidents, Journal of transport geography, 42, pp. 34 - 47. https://doi.org/10.1016/j.jtrangeo.2014.10.010 